\title{
Optimal Conditions to Improve the Performance of Chip-Based TLR Biosensor
}

\section{Queen's}

Chankyu Park ${ }^{\mathrm{a}}$, Alexandra Cunningham ${ }^{\mathrm{a}}$, Jennifer McLeod ${ }^{\mathrm{ab}}$, David Kelly $^{\mathrm{b}^{*}}$, Zhe She $^{\mathrm{a}^{*}}$

${ }^{a}$ Queen's University, Department of Chemistry, Kingston, ON, K7L 3N6, Canada

${ }^{\mathrm{b}}$ Royal Military College of Canada, Department of Chemistry and Chemical Engineering, Kingston, ON, K7K 7B4, Canada

\begin{tabular}{|c|c|c|}
\hline \multicolumn{3}{|c|}{ Introduction } \\
\hline \multicolumn{3}{|c|}{$\begin{array}{l}\text { Portable analytical devices with biorecognition elements are attractive for } \\
\text { many applications in environmental monitoring. Toll-like receptor } 2 \text { and } 6 \\
\text { are mixed to form heterodimer TRR2/6 and immobilized on the modified } \\
\text { gold surface and used to detect the Pam2CSKL. In this project, we } \\
\text { demonstrate the method of making chip-based biosensors with' }\end{array}$} \\
\hline \multicolumn{3}{|c|}{ Toll-Like Receptor } \\
\hline \multicolumn{3}{|c|}{$\begin{array}{l}\text { Toll- Like Receptors play an important role in the human innate immune } \\
\text { system and act as a first line of defense. They send signals through } \\
\text { protein-protecin interaction in the presence of toxins and damage on } \\
\text { tissues. Also, TLRs can detect a broad range of pathogens because TLRs are } \\
\text { a pattern recognition receptor that can detect Pathogen Associated } \\
\text { Molecular Pattern which are specific to bacteria. }\end{array}$} \\
\hline $\begin{array}{ll}\text { LLR Types } & {[1]} \\
\end{array}$ & Source $\mathrm{e}^{[1]}$ & Example $^{[1]}$ \\
\hline LR1/2 or $2 / 6$ & Gram-positive bacteria & Lipopeptides \\
\hline LR3 & Viruses & dsRNA \\
\hline $\mathrm{R} 4$ & Gram-negative bacteria & LPS \\
\hline $\mathrm{R5}$ & Bacterial flagellum & Flagellin \\
\hline
\end{tabular}

\section{Experimental}

Self-assembled monolayers are modified to contain two specific chemical groups at both nids for linting the bio-molecules onto surfaces, which are

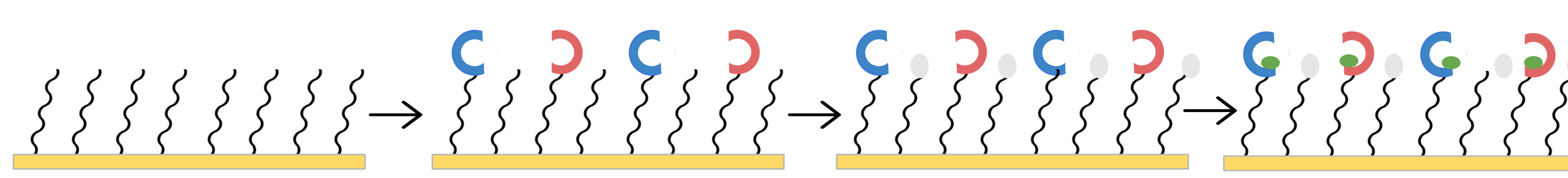

The finished sensors with BREs will be separated into batches with some tested right away and others stored in different conditions shown below

\begin{tabular}{|l|c|c|c|}
\hline Batch Number & $\mathbf{1}$ & $\mathbf{2}$ & $\mathbf{3}$ \\
\hline Conditions & In PBS solution at $4{ }^{\circ} \mathrm{C}$ & $\begin{array}{c}\text { In } 50 \% \text { glycerol } \\
\text { (v/v) PBS at }-33^{\circ} \mathrm{C}\end{array}$ & $\begin{array}{c}\text { Completely dried at } \\
-80^{\circ} \mathrm{C}\end{array}$ \\
\hline Testing Period & 2 weeks/1 month & 2 weeks $/ 1$ month & 2 weeks/1 month \\
\hline
\end{tabular}

A portion of sensors are tested immediately to detect various concentrations of Pam2CSK4 and the rest of the sensors are tested after

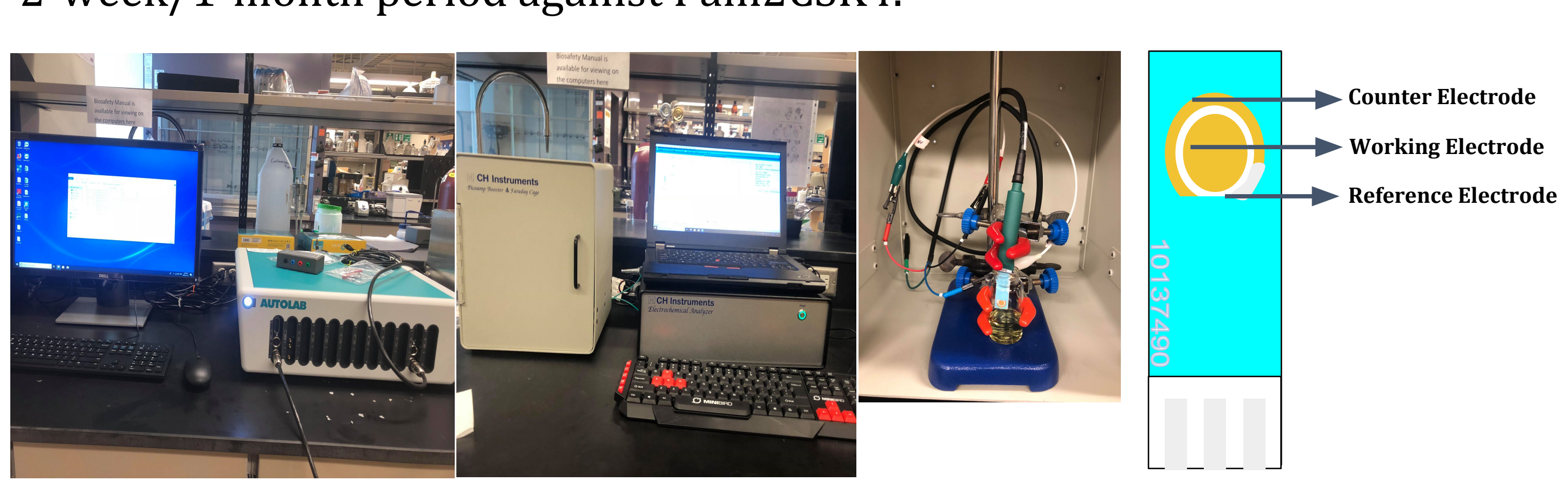

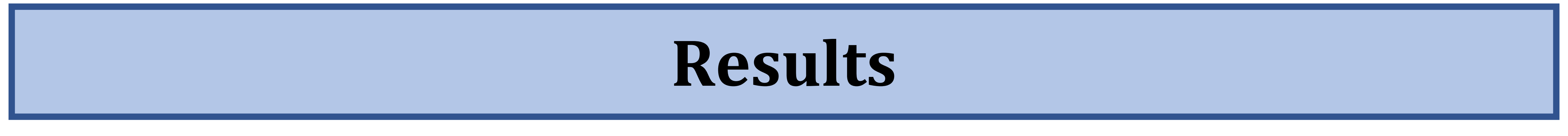

Tested against Pam2CSK4
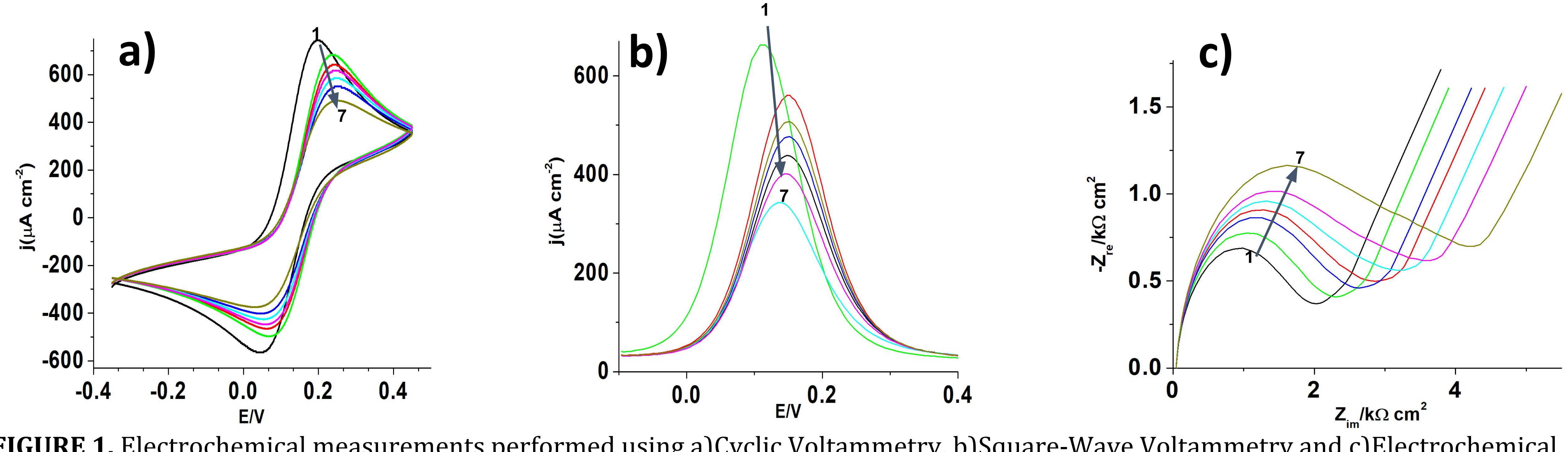

FIGURE 1. Electrochemical measurements performed using a)Cyclic Voltammetry, b)Square-Wave Voltammetry and c)Electrochemi weeks storage

\section{Different Storage Conditions}
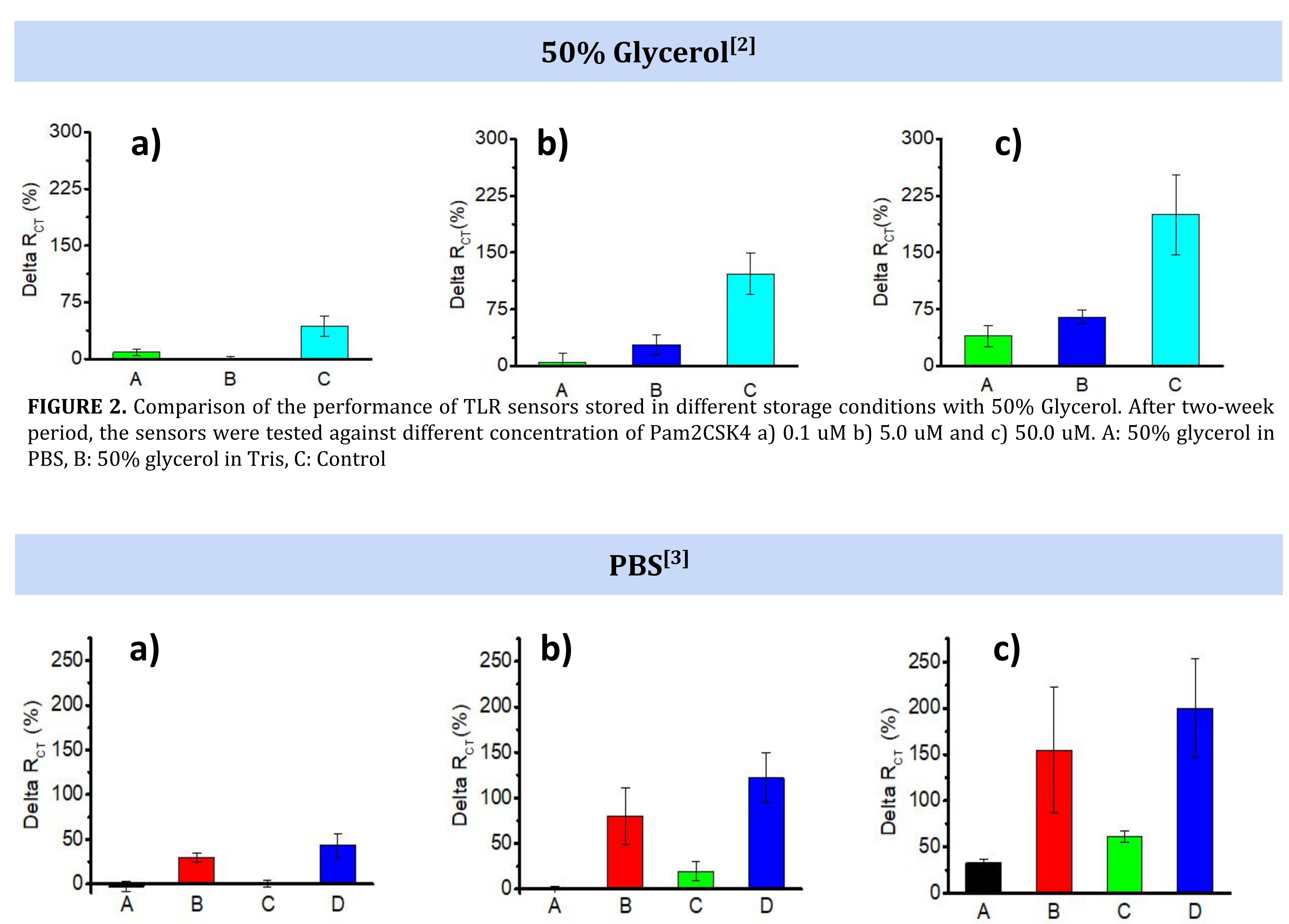

MGURE 3. Comparison of the performance of TLR sensors stored in different storage conditions with PBS. After two-week period sensors were tested against different concentration of Pam2CSK 4 a) $0.1 \mathrm{uM} \mathrm{b}$ ) $5.0 \mathrm{uM}$ and c) $50.0 \mathrm{uM}$. A: PBS at $4^{\circ} \mathrm{C}, \mathrm{B}$ : PBS at $-80^{\circ} \mathrm{C}$
C: Dry at $-80^{\circ} \mathrm{C}$, D: Control

\section{Discussion}

Portable chip-based TLR biosensors are exceptional because they can Also, the electrochemical approach of the sensor offers rapid and cost-effective measurements. For this reason, TLR biosensors will be used to monitor environmental samples in real-life.

However, in order for TLR biosensors to monitor samples in real-life, it Therefore, we have tried to preserve TLR biosensors using different buffer, temperature, and humidity. Our recent work was done with 3 conditions stated in 'Experimental.

TLR sensors were tested against different concentrations of Pam2CSK4 promising result as the performance of the chip dropped significantly. Also, in PBS conditions, only $\mathrm{PBS}$ at $-80^{\circ} \mathrm{C}$ maintained its performance.

\section{Future Work}

Currently, we have been building a multiplex sensor with differen Toll-like receptors and planning on testing stored chips against bacterias. Lastly, we would like to try new storage conditions using amino acids and hydroxylated additives.

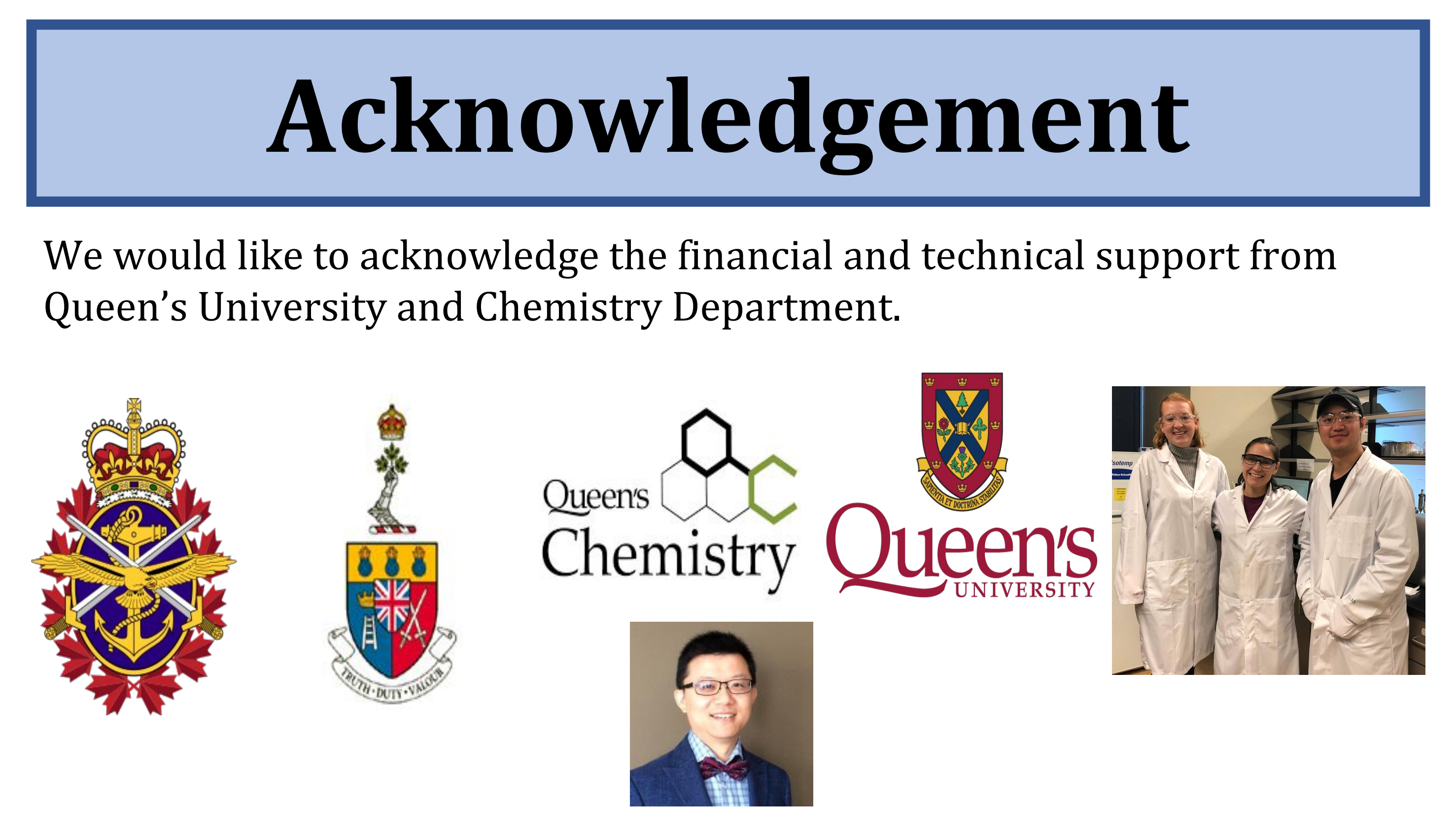

\section{References}

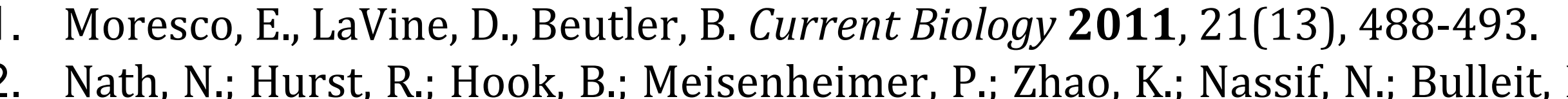
D.J Prote

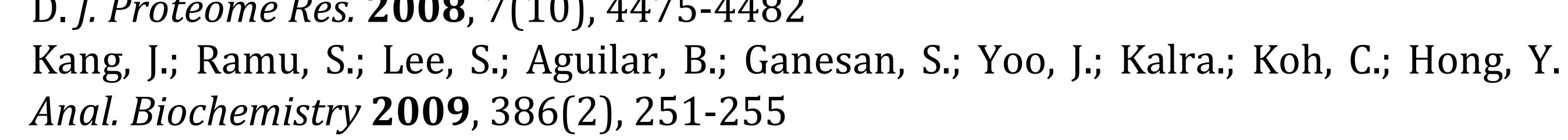

